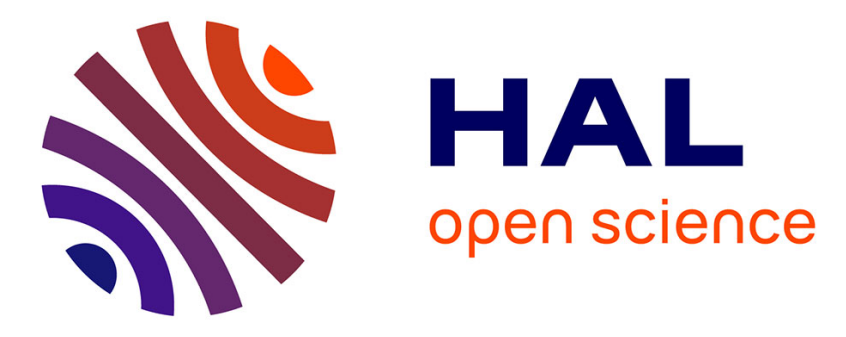

\title{
Characterization of an H2/O2 PEMFC Short-Stack Performance Aimed to Health-State Monitoring and Diagnosis
}

Raffaele Petrone, Carmela Vitagliano, Marie-Cécile Péra, Didier Chamagne, Marco Sorrentino

\section{To cite this version:}

Raffaele Petrone, Carmela Vitagliano, Marie-Cécile Péra, Didier Chamagne, Marco Sorrentino. Characterization of an H2/O2 PEMFC Short-Stack Performance Aimed to Health-State Monitoring and Diagnosis. Fuel Cells, 2018, 18 (3), pp.279-286. 10.1002/fuce.201700112 . hal-02131064

\author{
HAL Id: hal-02131064 \\ https://hal.science/hal-02131064
}

Submitted on 21 Oct 2021

HAL is a multi-disciplinary open access archive for the deposit and dissemination of scientific research documents, whether they are published or not. The documents may come from teaching and research institutions in France or abroad, or from public or private research centers.
L'archive ouverte pluridisciplinaire HAL, est destinée au dépôt et à la diffusion de documents scientifiques de niveau recherche, publiés ou non, émanant des établissements d'enseignement et de recherche français ou étrangers, des laboratoires publics ou privés.

\section{(c)(1)}

Distributed under a Creative Commons Attribution| 4.0 International License 


\title{
Characterization of an $\mathrm{H}_{2} / \mathrm{O}_{2}$ PEMFC Short-Stack Performance Aimed to Health-State Monitoring and Diagnosis
}

\author{
R. Petrone ${ }^{1,2 *}$, C. Vitagliano ${ }^{3}$, M.-C. Péra ${ }^{1,2}$, D. Chamagne ${ }^{1,2}$, M. Sorrentino ${ }^{3}$ \\ 1 FEMTO-ST, CNRS, Univ. Bourgogne Franche-Comte, rue Thierry Mieg, F-90010 Belfort Cedex, France \\ ${ }^{2}$ FCLAB, CNRS, Univ. Bourgogne Franche-Comte, rue Thierry Mieg, F-90010 Belfort Cedex, France \\ 3 UNISA, DIIN, University of Salerno, Salerno, Italy
}

\begin{abstract}
Proton exchange membrane fuel cell (PEMFC) is one of the most promising technologies in energy conversion. Nevertheless, improper operating conditions can severely affect the fuel cell (FC) lifespan. It is a matter of fact, that several degradation mechanisms could take place inside the cell in case of abnormal operating conditions. Among these, improper water managements, fuel quality and starvation conditions can show critical effects on PEMFC performance. Furthermore, if the exposure time to these faulty conditions resulted quite long, irreversible degradations and system ageing would occur. This work aims to investigate the impact of
\end{abstract}

\section{Introduction}

Nowadays, the increase of the greenhouse gases mainly due to the increasing $\mathrm{CO}_{2}$ concentration in the atmosphere leads people to pay particular attention to energy saving and converting technologies. Among the other, fuel cells (FCs) appear as promising devices. In this scenario, proton exchange membrane fuel cells (PEMFCs) are particularly attracting due to their high power density and quick start-up. Nevertheless, their durability keeps representing a relevant issue. It is a matter of fact that PEMFC performance and lifespan are directly related to the operating conditions. Faulty conditions can severely impact the stack performance, degenerating in irreversible degradation mechanisms and accelerating the FC ageing [1]. An overview of the main degradation mechanisms and the related faulty conditions can be found in [2-5]. When both improper water managements and reactants starvation conditions on $\mathrm{H}_{2} / \mathrm{O}_{2}$ PEMFC short-stacks performance. To this purpose, the experimental activity performed to characterize the stack health-state both in normal and abnormal conditions is presented. Particular attention is dedicated to the effects caused by improper conditions on stack electrochemical impedance spectroscopy (EIS) measurements' variations. Depending on the faulty conditions, the experimental results are then analyzed for health-state monitoring and diagnosis purposes.

Keywords: Diagnosis, EIS Spectra, Hydrogen/Oxygen PEM Fuel Cells, State-of-Health

one or more operating variables are affected from external environmental factors and/or improper system management conditions, a sudden change in stack performance can be observed. As a consequence some stack measurements, such as voltage output and electrochemical impedance spectroscopy (EIS) can represent generic tools to detect faulty conditions. In this context, the European Project HEALTH-CODE faces the challenge of delivering a monitoring and diagnostic tool able to evaluate the current state-of-health (SoH) of a PEMFC. According to the HELTH-CODE objectives, this work focuses on the EIS measurements oriented to develop FC on-field monitoring and diagnosis approaches. Depending on the electrochemical processes occurring inside the FC the shape of the EIS spectrum on the Nyquist diagram can vary in different ways. Usually, in nominal conditions the superposition of two arcs can be observed; the first one related to the charge transfer losses and the second one coupled to the diffusion processes [6]. Nevertheless, if the diffusion losses are negligible 
only one arc is detected. Furthermore, the spectra intersections with the real axis give the resistances values at high and low frequencies, mainly corresponding to the electrolyte and polarization resistances, respectively. It is worth noting, that the polarization resistance is composed by the sum of the electrolyte resistance and the real value of the Faraday impedance at low frequencies; the last one taking into account both the charge transfer and diffusion processes [6]. As both the shape and magnitude of the EIS spectra change with respect to the FC operations, both nominal and faulty conditions are considered in this paper. In order to anticipate the fault, the diagnostic algorithm must be able to identify the different phenomena, so as to promptly enable suitable recovery actions. To distinguish and isolate the different faults a series of features are proposed in the following. It is worth noting that this paper reports on the results of a preliminary study aimed to select a suitable common set of features to be used on different diagnostic approaches $[7,8]$, and particularly on data-driven methods [9]. Features selection is performed combining the impedance spectra analysis both on the Nyquist and Bode (magnitude and phase) diagrams. The following main features resulted:

(i) The high frequency resistance (also corresponding to the lowest magnitude value): $R_{h f}$

(ii) The polarization resistance (also corresponding to the high magnitude value): $R_{p}$

(iii) The difference between $R_{h \mathrm{f}}$ and $R_{p}$ (also corresponding to the real part of the Faraday impedance at low frequencies): $D_{F}$

(iv) The maximum absolute phase: $m_{p}$

(v) The frequency of $m_{p}: f_{m p}$

(vi) The frequency of the high magnitude value (also corresponding to the frequency at which the impedance spectra is closed to the real axis at low frequencies): $f_{R p}$

It is possible to notice that some analogies can be found, especially between the spectra magnitude values into the Bode diagram and the high and low frequencies resistances into the Nyquist plot. Therefore, to avoid redundancy of information the magnitude values are not considered to add features. Nevertheless, the frequency related to $R_{p}$ value varies with the spectra deformations, suggesting observing the maximum magnitude frequency variation. Furthermore, $m_{p}$ and $f_{m p}$ are introduced to take into account the spectra growth at medium frequencies. Improper water management, which usually induces drying/flooding conditions, as well as inappropriate gas management causing low reactants stoichiometry conditions, are investigated in this paper. To give some examples, dried conditions directly reduce the electrolyte proton conductivity, causing high frequencies' resistance to increase. Furthermore, the decrease of the activation reaction at the electrodeelectrolyte interfaces, caused by the reduction of the water content, also induces the charge transfer losses' growth. Although these phenomena are recoverable, a long-term exposure will accelerate the carbon corrosion and the $\mathrm{Pt}$ dissolution and agglomeration processes, thus leading to mechanical degradations [3]. In this case an irreversible EIS spectra defor- mation can be observed. On the other side, the accumulation of water, well known as flooding, affects the reactants' transport to the catalyst layers. This phenomenon can be directly inferred from the diffusion losses' increase. However, if the accumulated water is not opportunely removed, local starvation phenomena are induced. The main effect of the reactant starvation is the reverse potential condition, which induces carbon oxidation at the anode side [2-5]. This condition, as for flooding, is mainly observable from the increment of the Faraday impedance (charge transfer losses and diffusion arc growth). These points will be clarified in the next sections. It is worth noting, that this work does not specially focus on degradation analysis, but it is rather oriented toward stack performance characterization under normal, faulty and degraded conditions. To this purpose, a $\mathrm{H}_{2} / \mathrm{O}_{2}$ PEMFC short-stack is tested to evaluate the impact of the faulty conditions in the EIS spectra. The relevant features extraction for fault detection and isolation (FDI) procedures' development is the final objective. Experimental activity description is introduced in Section 2. Subsequently, the short-stack preliminary characterization under nominal and improper operating conditions is presented in Section 3. Particular attention will be payed to induce faults consistently with the system real operating conditions; physical constraints and measurements stability conditions are also evaluated. The impact of both the faulty conditions and their related degradation mechanisms onto the EIS spectra is deepened within section 4 . Finally, considerations and conclusion are drawn at the end of the manuscript.

\section{Experimental}

\subsection{Activity Set-Up and Objectives}

This section introduces the experimental activity set-up dedicated to the characterization of the $\mathrm{H}_{2} / \mathrm{O}_{2}$ PEMFC shortstacks. During this step, the FC integration on the laboratory test bench and tests' protocol development are considered. Stacks are provided by the Electro Power Systems Manufacturing Srl (EPS). The short-stack consists of 8 cells having an active area $\left(S_{a}\right)$ of $200 \mathrm{~cm}^{2}$. Tests are scheduled to reproduce the real EPS back-up system operations. Therefore, as suggested in the EPS manual, tests were performed between 0 and $240 \mathrm{~A}$. It is worth noting, that the value of $240 \mathrm{~A}\left(1.2 \mathrm{~A} \mathrm{~cm}^{-2}\right)$ corresponds to the system operation limits. Nevertheless, the stack is able to work also at higher current values (more than 300 A). Real system operates with reactants' recirculation. Concerning reactants' inlets, pressures are fixed at $1.3610^{5} \mathrm{~Pa}$ and $1.4210^{5} \mathrm{~Pa}$ for the anode and cathode side, respectively, whereas overstoichiometry factors are set at 1.9 and 2.9 for hydrogen and oxygen, respectively. These values are fixed, considering the reactants' flow rates during system operation in nominal condition. Both the reactants relative humidity rates $(R H)$ are fixed at $50 \%$ in a range of $\pm 10 \%$. Finally, the stack outlet temperature of the cooling circuit is assumed as the stack working temperature. Its value is kept constant at $335 \mathrm{~K}$ in a range of \pm 5 degrees. To perform the experimental activity, an FCLAB 
in-house test bench is adapted to work with oxygen; electrical, fluidic and thermal variables are controlled. Data are recorded all along the test. Furthermore, a home-made device developed to perform EIS measurements, both at high current and voltage conditions, is used. After the pressure tests, the warmup and the conditioning, the measurements at the beginning of life (BoL) are performed, in accordance to the standard fixed in HEALTH-CODE protocol. The stack was characterized by using polarization curves and EIS measurements. The same measurements are carried out all along the experimental activity. Concerning $I-V$ curves, a step by step current-decreasing (from $240 \mathrm{~A}$ to $0 \mathrm{~A}$ ) and a step-by-step current-increasing (from 0 A to $240 \mathrm{~A}$ ) profile is adopted. Moreover, three reference operating conditions are selected at 45, 120 and $210 \mathrm{~A}$ to perform EIS. The first value, corresponding to $0.225 \mathrm{~A} \mathrm{~cm}^{-2}$, is fixed to study the stack state-of-health $(\mathrm{SoH})$ at low current densities. The limitation of $0.2 \mathrm{~A} \mathrm{~cm}^{-2}$ is met in order to avoid additional degradations, which are not related to the faulty conditions under examination. In order to meet system limitation in terms of the maximum operation at $240 \mathrm{~A}$, the maximum reference current value for EIS was set at $210 \mathrm{~A}$ $\left(1.05 \mathrm{~A} \mathrm{~cm}^{-2}\right)$, which is the nominal operating condition. To validate this choice, the EIS measurements at 240 A were also performed; no relevant difference in EIS spectra shapes could be observed between 210 and 240 A conditions. Finally, the medium value is set at $120 \mathrm{~A}\left(0.6 \mathrm{~A} \mathrm{~cm}^{-2}\right)$. A frequency range from $6 \mathrm{kHz}$ up to $100 \mathrm{mHz}$ is set for measurements; 10 points per decade are considered. Measurements are performed in floating mode in a galvanostatic configuration; a multi-electrode connection is used. Particularly, during the EIS measurements the stack is stimulated with a repetition of 8 sinusoidal signals per each point (single-frequency approach), from high frequencies to low frequencies. An amplitude of 6 A (pick-topick) is assumed. This amplitude value was previously set to verify both the linearity and causality conditions for measurements. The value of 6 A resulted enough to be higher than the system noise and at the same time, to be not so high to change the stack equilibrium. In this way, the measured response is entirely caused by the superposed perturbation. To perform EIS, the in-house device controls in remote the dynamic electronic load to superpose the AC signal during EIS measurements. The spectrometer uses a control board for the load demand and an acquisition board, both for DC and AC signals measurements. The signal processing is obtained exploiting the fast Fourier transform (FFT); signal stability and linearity conditions for FFT are verified during the process to insure measurements validity. The spectrometer is able to measure in parallel both the stack impedance and the single cell impedance. Concerning the considered setting parameters a period of about 6 minutes is required to obtain the whole spectrum. It is worth noting, that only one cell spectrum can be measured in parallel to the stack measurements, therefore to obtain all the single cells spectra, measurements must be performed in series. At the end of the measurements, all the stack spectra obtained in parallel during the cell spectra measurements are compared to verify the measurements repeatability. In the framework of the HEALTH-CODE project, with the aim of developing suitable on-board monitoring and diagnosis procedures based on stack voltage and EIS measurements, the main recurrent and relevant faulty conditions are analyzed. Among the ones scheduled within the project, improper water management and reactants local/global starvations are introduced in this work. In the first part of the project, experimental activity is aimed to characterize the different PEMFCs technologies $\left(\mathrm{H}_{2} /\right.$ air and $\left.\mathrm{H}_{2} / \mathrm{O}_{2}\right)$, so as to generate suitable data for the diagnostic algorithms improvement. Different approaches are considered: model-based, data-driven and signal-based. All these methods have a common need: identify the main signatures/features in data set able to detect and isolate the faulty conditions. To this purpose, the first characterization tests for the $\mathrm{H}_{2} / \mathrm{O}_{2}$ PEMFC short-stack are presented in the next section. The main objective of this work is to set the improper operating conditions which can occur in real systems and their impact in EIS measurements. To achieve these goals, two preliminary steps are followed. The first one is the definition of specific test matrix for test repeatability. The second one consists in measurements analysis to verify the stack $\mathrm{SoH}$ variation with respect to the different improper operating conditions and the induced degradations.

\section{Results and Discussion}

\subsection{System Characterization from Nominal to Improper Faulty Conditions}

The first characterization is performed at nominal conditions. In accordance with the EPS system specifics, the reference values for the test matrix development in nominal conditions are those proposed in Section 2. Figure 1 shows the short-stack polarization curve at the beginning-of-live (BoL) for an equivalent cell. The upper black line represents the current-decreasing measurements, while the lower black line is obtained during the current-increasing profile; discontinuities

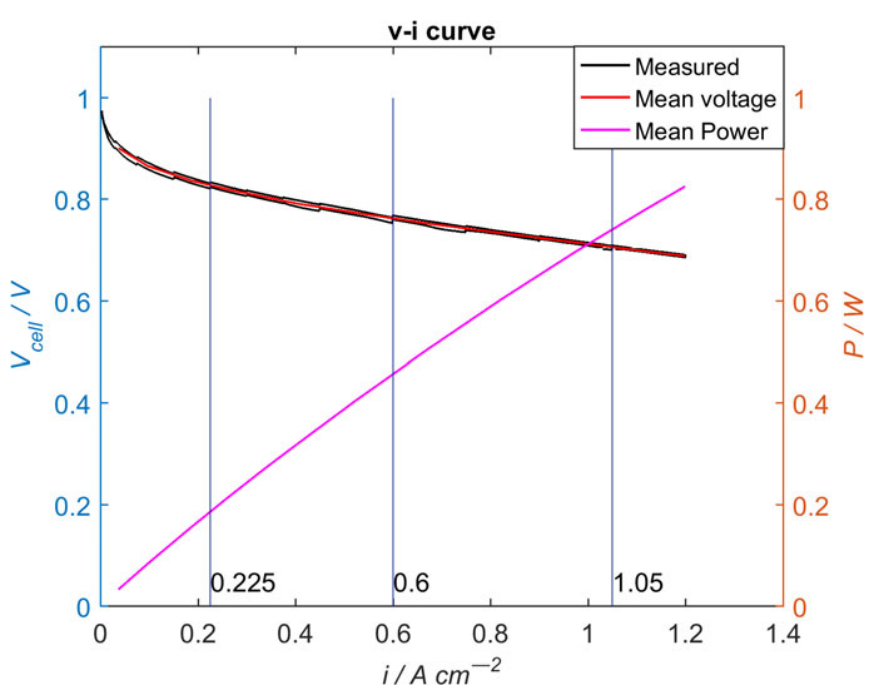

Fig. 1 Reference polarization curve at the beginning-of-life (BoL). 
are due to the voltage stabilization during current steps' duration. It is worth noting, that the black lines showed the continuous measurements. The resulting average $I-V$ curve is shown in red, while the equivalent cell power $\left(W=V n_{c}^{-1} I_{c m}^{-2}\right)$ is represented in magenta, whereas $n_{c}$ is the number of stack cells. The power trend shown in figure 1 is obtained from the average voltage curve as discrete points. Finally, the reference values for EIS measurements are highlighted with the blue lines. In Figure 2, the equivalent EIS spectra $\left(Z_{\text {eq }}\right)$ acquired in nominal conditions are reported. It is possible to observe that no diffusion arc can be detected, probably due to the fact that oxidant gas is pure oxygen and high over-stoichiometry factors are considered. However, to check the presence of mass transport at higher current densities, the cyan EIS spectrum was measured at $270 \mathrm{~A}\left(1.35 \mathrm{~A} \mathrm{~cm}^{-2}\right)$. Results confirmed that also at a current as high as 270 A diffusion losses are still negligible. Therefore, it is possible to state, that during the system operation in nominal conditions, only one arc can be detected on the EIS spectra, for the short-stack under examination. It is worth underlining, that per each test, the system is operated at stable conditions waiting for operating variable stabilization (at least 10 minutes) before to start the EIS measurements. Once the reference spectra were acquired, short-stack was operated under improper operating conditions. During this step, the operating variables were stressed from their nominal values to the critical ones; variations were firstly performed separately, keeping constant the other variables, and then coupling the effects. Particularly, temperature variations showed that no sensible spectra variations can be observed at the different current levels in a range of \pm 5 degrees. Furthermore, reactants' over-stoichiometry variation tests confirmed the high nominal over-stoichiometry values both at anode and cathode side. In fact, it is possible to reduce of about $30 \%$ the value of the stoichiometric factor for hydrogen and of about $55 \%$ the reference value for oxygen, before to state a little variation in stack voltage response. These tests were fundamental for the test matrix development and stack characterization in faulty conditions, which results from a combination of different factors, as described in the following. In order to induce flooding conditions, the reactants' relative humidity $(R H)$ was increased from $50 \%$ to $100 \%$. However, this condition resulted

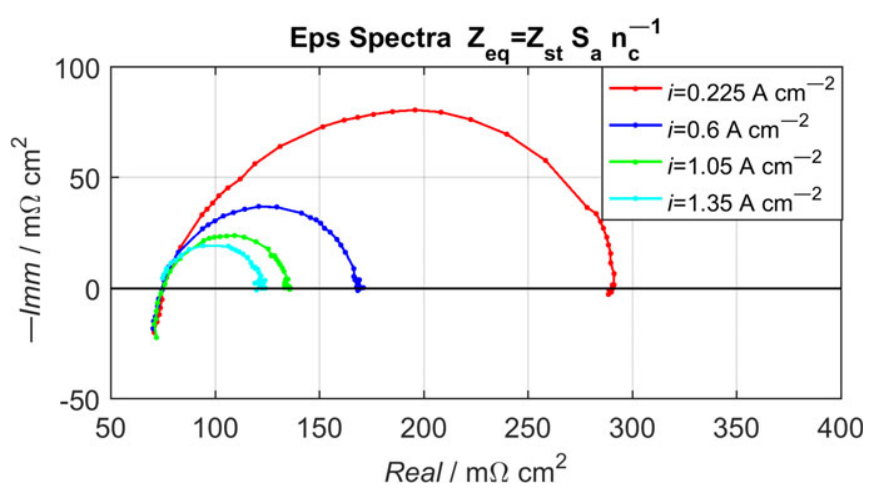

Fig. 2 Reference EIS spectra at 45, 120, 210 and 270 A. not sufficient, due to the reactants high flow rate. Therefore, mixed conditions were tested. Stack temperature was reduced by 4 degrees to promote the water condensation on the cells' channels, while the reactants flows were reduced by $10 \%$ both at anode and cathode sides to prevent water removal. Time exposure was also considered. Results are reported in Figure 3, where it is possible to observe that $210 \mathrm{~min}$ are required to start flooding conditions (not completely attained). New tests were performed on a second short-stack, reducing by $20 \%$ and $50 \%$ the reactants over-stoichiometry at anode and cathode sides, respectively. In this case 30 minutes are sufficient to induce flooding and detect the diffusion arcs in the EIS spectra at the different current levels. Stack nominal performance are successfully recovered by purging the cells and increasing the gases' flow rate. Nevertheless, test duration must be carefully controlled in order to avoid local reactants' starvations, caused by the presence of the accumulated water. The new tests results are shown in the next section (Figure 7). To induce local starvation and incipient global starvation conditions, the substoichiometry tests were performed. Oxygen stoichiometric factor $\left(\lambda_{\mathrm{O} 2}\right)$ is then decreased step by step waiting 30 minutes per step; all the other operating parameters are unvaried. The first sensible performance variation resulted at $\lambda=1.1$, both in the stack voltage and spectra. Subsequently, the oxygen stoichiometry was reduced to 1 , thus inducing a sudden voltage drop. Therefore, to recover the voltage performance, the oxygen stoichiometric factor was gradually increased. It is worth noting, that at $\lambda=1$ the EIS measurement was not performed under optimal stationary conditions. Results are shown in Figure 4. It is possible to notice how the diffusion losses start increasing during local starvation conditions induced in case of $\lambda=1.1$. With the achievement of the global starvation conditions, a sensible growth of the charge transfer losses can be observed and the diffusion arc is finally detected. In fact when the stoichiometric factor is set to 1 the voltage of the last cell of the stack starts to decrease while the other ones are quite stable. All the other operating variables are constant; all EIS measurements started as soon as possible, as all the operating variable are stable. Stability of the stack output voltage is verified through the spectrometer during the signal processing.

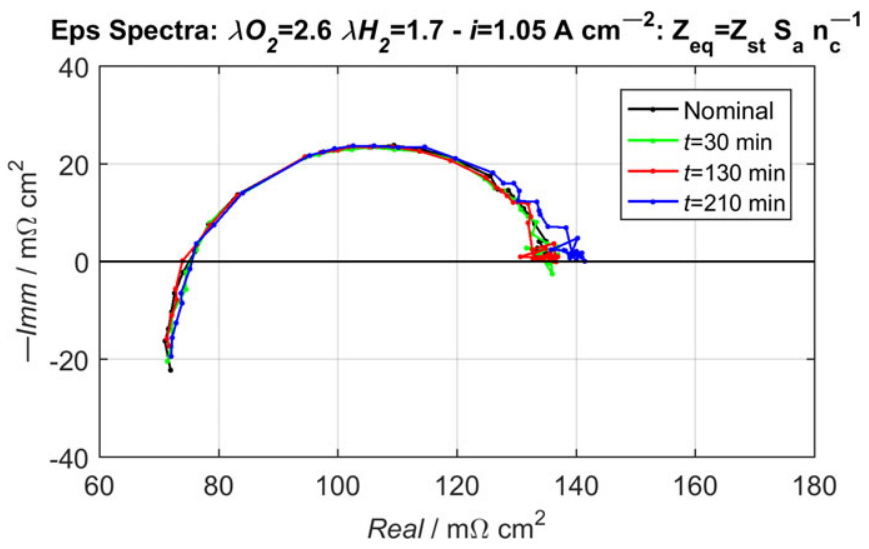

Fig. 3 EIS spectra during the first flooding test at $210 \mathrm{~A}$. 
Nevertheless, at the end of the test (at low frequencies) the stoichiometric factor was opportunely varied from 1 to 1.3 to recover the voltage drop increasing. This change influenced the last points of the impedance spectra, as observable in the diffusion arc of the red curve presented in figure 4 . It is worth noting, that this first characterization is performed to check the operating variables limits to obtain stable measurements. Nevertheless, in case of reactants' starvation a sudden voltage drop occurs, affecting the measurements stability at low frequencies. Different tests shown the same behavior. These tests severely affected the FC SoH, inducing both recoverable and unrecoverable degradation mechanisms; for more details the reader is addressed to the next section. Subsequently, drying tests were performed. To this purpose reactants' $R H$ was reduced from $50 \%$ to $20 \%$. Contrary to the flooding test, it is not necessary to vary also the reactants flows and the stack temperature to generate dried conditions. Figure 5 shows the typical spectra shift due to the membrane resistance growth. It is worth noting, that tests results are influenced by the unrecoverable degradations induced by the previous oxygen starvation, the impact of which in EIS spectra deformation is given by the black curve in Figure 5. The blue curve shows the recoverable effect of the drying conditions. Nevertheless, only drying effects can be recovered and initial reference (green spectrum) shape is not obtained. Therefore, new tests are performed on a second stack to validate results in drying conditions. In this case, a clear membrane resistance growth with associated charge transfer arc growth is stated. During these

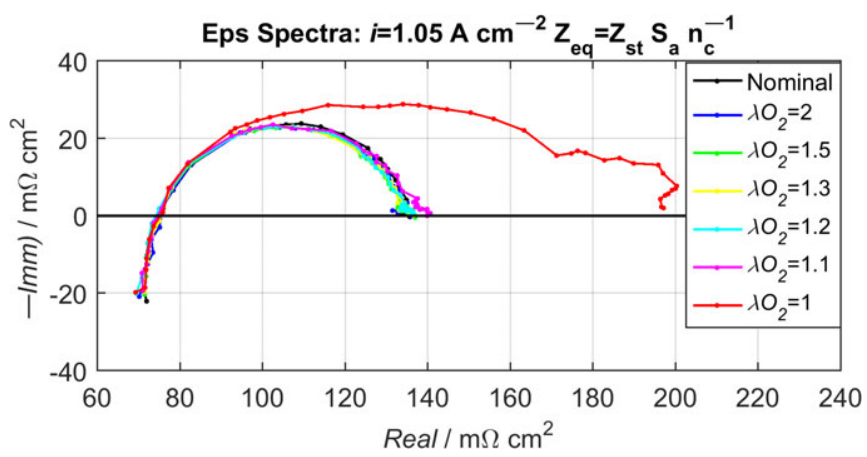

Fig. 4 EIS spectra under oxygen sub-stoichiometry test at $210 \mathrm{~A}$.

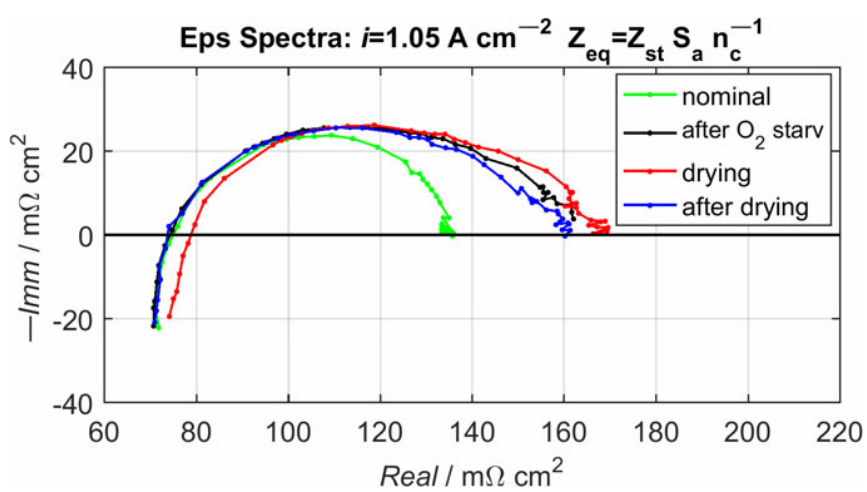

Fig. 5 ElS spectra under drying test at $210 \mathrm{~A}$. tests, the stack was previously operated during 30 minutes at low current conditions ( $I=45 \mathrm{~A})$ to induce drying conditions. As for flooding, an example of the new measured spectra in case of drying is given and commented in the next section (Figure 7). Finally, the hydrogen sub-stoichiometry test was performed. Like for oxygen sub-stoichiometry test, any relevant variations are observed until $\lambda=1$.1. In order to observe the effects of the hydrogen sub-stoichiometry, three spectra are acquired in series. During this test the stoichiometric factor was reduced from 1.1 to 1 and when the operating variable becomes stable the EIS measurements start. The impedance spectra were acquired with an interval of about 5 minutes. Results are shown in Figure 6; to underline the fact that the cell voltage varied during the measurements depending on the time operated at $\lambda_{H 2}=1$ the related spectra are named with dynamic 1, 2 and 3. Dynamic 1 represents the first measurements and then, the beginning of the diffusion losses growth can be stated. It is possible to state that the impedance spectra increase depending on the evolution of the single cell voltage drop. Nevertheless, an unexpected behavior was observed at after dynamic 3, where the cells' voltage trend recover a stable condition. This allowed the magenta spectrum measurement. Therefore, the first measurements under dynamic conditions show the measurements drift during transitory conditions, while the last one is the impedance spectrum measured in stable conditions in case of fuel starvation. Nevertheless, the fact that the voltage output resulted stable during the last test suggested that the global starvation condition was not achieved. Like for oxygen starvation, also these tests induce unrecoverable degradations. New tests are actually on-going to validate both hydrogen and oxygen sub-stoichiometry results. Because the stack is operated in pressured condition new tests are scheduled changing both the stoichiometric factor and the back-pressure valve control.

\subsection{Faulty Conditions: Performance Losses and Degradations in EIS Spectra}

Once the preliminary characterization tests' activity was performed, the improper operating conditions for test repeatability are fixed. Therefore, new tests are performed (currently

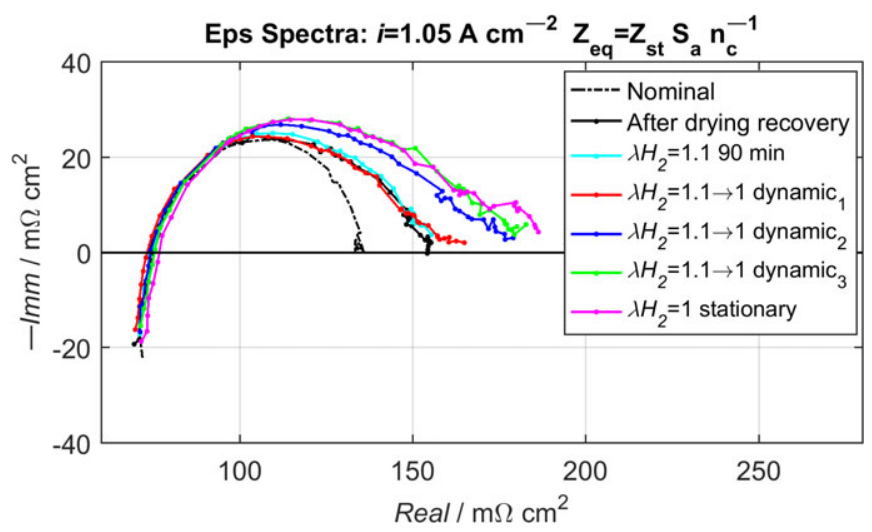

Fig. 6 EIS spectra under hydrogen sub-stoichiometry test at $210 \mathrm{~A}$. 
on-going) to study the impact of different level of fault per each fault. The operating variables limitations are also fixed to avoid unrecoverable degradations during the tests. This section reports the main results obtained during this preliminary study aimed to highlight the relevant features for PEMFC diagnosis approaches based on EIS measurements. Tests performed in case of flooding and drying conditions show interesting results. As reported in Figure 7, the flooding conditions affect mainly the diffusion losses, resulting in the Faraday impedance growth at the different current levels [10]. Particularly, the presence of the diffusion arc can be detected at the lower frequencies (starting at about $10 \mathrm{~Hz}$ ), while at high frequencies not many variations can be observed. Therefore, considering the features introduced in Section 1, an increment of the $R_{p}, D_{F}$ and $f_{R p}$ values can be stated in Table 1 . Nevertheless, the values of $m_{p}$ and $R_{h f}$ resulted quite unvaried (less than $3 \%$ of variation), which is mainly due to the fact that any spectra shape deformation is observable until $10 \mathrm{~Hz}$. It is worth noting, that this behavior is related to the technology of the stack under examination. In fact in case of flooding the variation of the maximum absolute phase value and the related frequency is also expected. On the other hand, in case of drying an initial spectra variation can be observed at high frequencies
[10]. The arc shift is mainly due to the electrolyte ionic conductivity reduction caused by the membrane drying. Moreover, a clear growth of the charge transfer losses can be also noted. In this case all the features $\left(R_{h f}, R_{p}, D_{F}, m_{p}, f_{m p}\right.$ and $\left.f_{R p}\right)$ values proposed in Section 1 are varied (refer to Table 1). Therefore, it is possible to detect and separate these two different processes by monitoring the different losses behavior. For a better understanding, the impedance spectra presented in Figure 7, both at nominal and faulty conditions, are reported into the Bode diagrams of Figure 9. While Table 1 proposes the behavior of the features values in case of flooding and drying conditions. It is worth noting, that the data presented in Table 1 are obtained from the second test campaign performed on a new shortstack. Therefore, the reference features' values obtained for nominal conditions can differ from the ones presented in Table 2, that are referred to first test campaign. The slight difference is mainly due to a major connection resistance, probably related to the short-stack manufacturing. Subsequently, in Figure 8 the EIS spectra deformations in case of reactants' starvation are shown; BoT is the reference spectrum at the beginning of the test. It is possible to notice that, like for flooding not sensible variation can be observed at high frequencies. Nevertheless, an higher growth of the Faraday impedance,

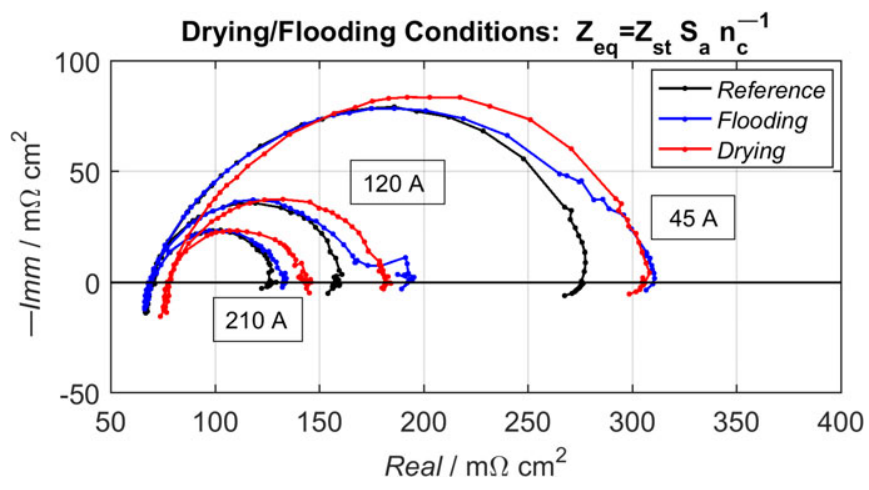

Fig. 7 EIS spectra deformation in case of drying and flooding conditions.

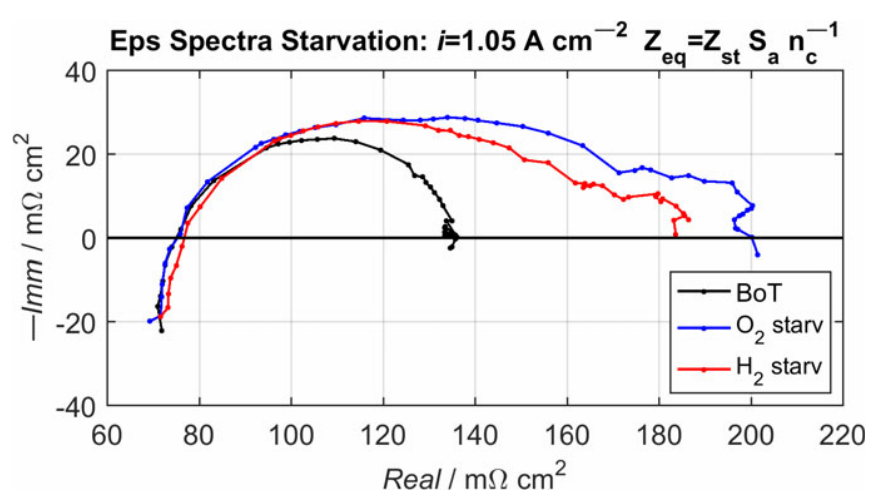

Fig. 8 EIS spectra deformation in case of starvation at $210 \mathrm{~A}$.

Table 1 Features' behavior in case of flooding and drying conditions (second test campaign, short-stack 2).

\begin{tabular}{|c|c|c|c|c|c|c|}
\hline \multirow[t]{2}{*}{ Operating Conditions } & \multicolumn{6}{|l|}{ Features } \\
\hline & $R_{h f} / \mathrm{m} \Omega \mathrm{cm}^{2}$ & $R_{p} / \mathrm{m} \Omega \mathrm{cm}^{2}$ & $D_{F} / \mathrm{m} \Omega \mathrm{cm}^{2}$ & $m_{p} /^{\circ}$ & $f_{m p} / \mathrm{Hz}$ & $f_{R p} / \mathrm{Hz}$ \\
\hline Nominal & 71.70 & 126.29 & 54.59 & 13.36 & 540 & 6 \\
\hline Flooding & 69.85 & 133.39 & 63.54 & 13.59 & 420 & 0.5 \\
\hline Drying & 77.20 & 142.85 & 65.65 & 12.58 & 480 & 0.7 \\
\hline
\end{tabular}

Table 2 Features' behavior in case of reactants' starvations (first test campaign, short-stack 1).

\begin{tabular}{|c|c|c|c|c|c|c|}
\hline \multirow[t]{2}{*}{ Operating Conditions } & \multicolumn{6}{|l|}{ Features } \\
\hline & $R_{h f} / \mathrm{m} \Omega \mathrm{cm}^{2}$ & $R_{p} / \mathrm{m} \Omega \mathrm{cm}^{2}$ & $D_{F} / \mathrm{m} \Omega \mathrm{cm}^{2}$ & $m_{p} /^{\circ}$ & $f_{m p} / \mathrm{Hz}$ & $f_{R p} / \mathrm{Hz}$ \\
\hline Nominal & 76.02 & 136.08 & 60.06 & 12.99 & 540 & 0.4 \\
\hline $\mathrm{O}_{2}$ Starv. & 75.98 & 201.51 & 125.53 & 14.05 & 300 & 0.1 \\
\hline $\mathrm{H}_{2}$ Starv. & 77.60 & 183.69 & 106.09 & 14.09 & 360 & 0.1 \\
\hline
\end{tabular}


due to both the charge transfer and diffusion losses, can be observed [11,12]. In this case the spectra shape deformation can be previously observed at about $100 \mathrm{~Hz}$, both in case of oxygen and hydrogen starvations. Finally, it is possible to notice that, hydrogen starvation that affects the anode side, results in lower measurable Faraday losses with respect to the oxygen one at the cathode side. In this case, excepted $R_{h f}$, all the features values are affected obtaining different values per each fault (refer to Table 2). As for improper water management conditions also the spectra obtained under reactants' starvation conditions are proposed in Figure 9. Flooding and drying results are referred to the stack 2 , while reactants' starvation measurements are referred to stack 1 .

It is worth noting, that if different level of losses can be detected for the different phenomena, for fault isolation more information could be required. To give an example, similar features behaviors, but of different intensity, can be found in case of flooding and reactants' starvation. This behavior is probably due to the fact that, the presence of the accumulated water into the channel can induce the reactants local starvation representing a limit condition between flooding and incipient global starvation. In order to anticipate the fault, the diagnostic algorithm must be able to identify these different phenomena. Therefore, new studies are under processing to distinguish and isolate the different faults. To this purpose, current works are dedicated to test several sets of features for the different diagnostic approaches. In Figure 10 the effects of the system ageing on the EIS spectra at $210 \mathrm{~A}$ is showed. The black spectrum is the reference one at the beginning-of-test (BoT). The blue spectrum shows the impact of unrecoverable losses resulting after the $\mathrm{O}_{2}$ starvation test; the stack recovering procedure was performed before the EIS measurements. The red spectrum is measured after the recovering procedure
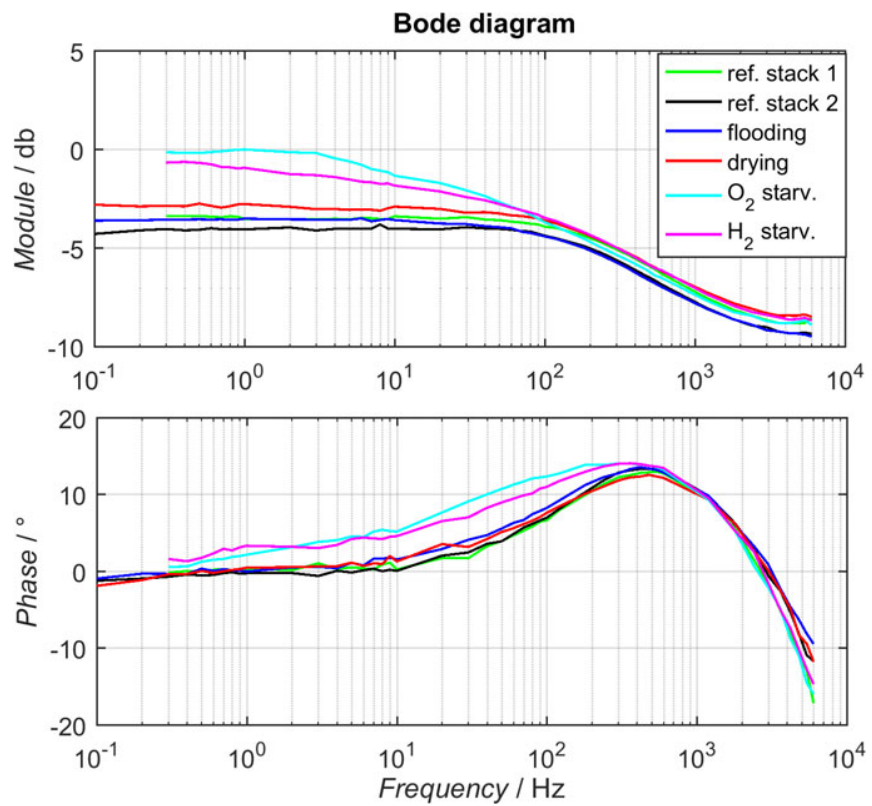

Fig. 9 Magnitude and phase Bode diagrams: EIS measurements at $210 \mathrm{~A}$ under nominal and faulty conditions.

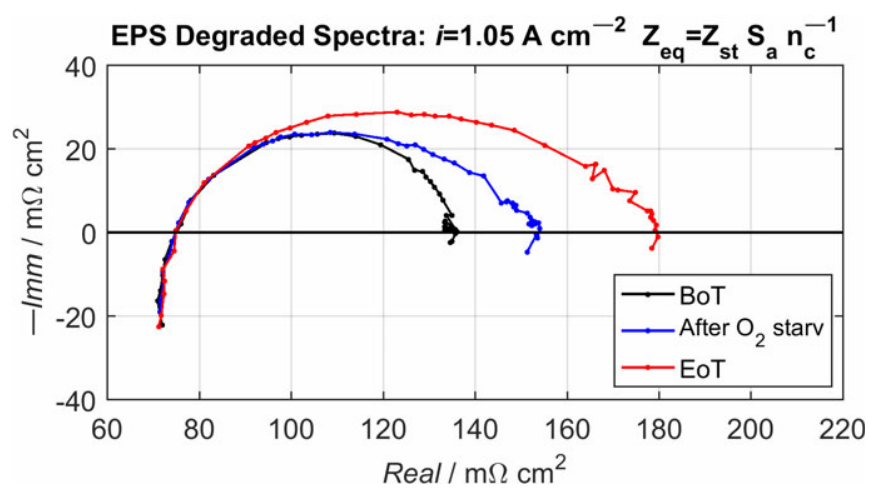

Fig. 10 Degraded spectra at $210 \mathrm{~A}$.

at the end-of-the test (EoT). It is worth noting, that between the red spectrum and the blue spectrum, both drying and $\mathrm{H}_{2}$ starvation tests are performed. Considering that both flooding and drying tests do not introduce unrecoverable degradation, it is possible to observe the impact of reactants' starvations. Particularly, it is possible to observe a progressive growth of the Faraday impedance, resulting in the charge transfer arc increasing. According to Borup et al. [2] and de Brujin et al. [3], reactants starvations induce an unrecoverable electrochemical surface area reduction, probably related to carbon corrosion [13] and platinum dissolution/agglomeration phenomena. If these phenomena are well-known for fuel starvation, few information can be found in literature concerning the degradations induced by oxygen starvation, and particularly for $\mathrm{H}_{2} / \mathrm{O}_{2}$ PEMFC. This is probably due to the fact that usually fuel starvation results more detrimental than oxygen starvation conditions [3]. Some authors [3,4,14,15] stated that oxygen starvation also caused the electrocatalyst degradation phenomena. When oxygen concentration is depleted at the cathode side, the oxygen reduction reaction is replaced by proton reduction, producing hydrogen at the cathode side instead of water $[3,4,14]$. In this scenario, a slightly reversal potential condition occurs; this phenomenon increases rising of the load demand [14]. Although this phenomenon appears less detrimental in terms of carbon and backing layers corrosions with respect to the fuel starvation condition, both the loss of surface area of the cathode platinum particles $[3,4,14]$ and the presence of hot spot $[14,15]$ are stated at the cathode side. The results of the oxygen starvation test previously presented confirmed these degradation phenomena, showing the unrecoverable Faraday's impedance growth. In accordance with [14], the high load demand (210 A) set during the test amplifies the degradation phenomena, which resulted not negligible for the $\mathrm{H}_{2} / \mathrm{O}_{2}$ PEMFC under examination. Moreover, the Faraday impedance growth could be also associated to an increment of the mass transport losses, due to a partial electrodes hydrophobicity loss. Some drying tests are performed before the end of the test (EoT). After these tests the short-stack recovered part of the induced degradations at the start-up (for a short period); nevertheless, as the nominal values of the reactants relative humidity were achieved, the effect of the partial recovery disappeared. This behavior could suggest a possible change in 
electrodes hydrophobicity. Therefore, when the accumulated water is removed a partial recovery of the mass transport losses can be observed. Nevertheless, as the system come back to the nominal conditions improper water accumulation phenomena occur. At the end-of-test (EoT) an interesting conclusion can be deduced. In case of ageing, the spectra deformation is consistent with the fault that induces the degradations. In this case, the considered features are consistent with the values observed in case of the reactants starvations. Therefore, analyzing also the degraded spectra deformation appears a mandatory point to develop adaptive diagnostic tools. This kind of approach will be the subject of future works.

\section{Conclusions}

The experimental activities carried out to characterize $\mathrm{H}_{2} / \mathrm{O}_{2}$ PEMFC short-stack operations are presented in this work. Tests are oriented to generate improper operating conditions, so as to fruitfully support the development of advanced monitoring and diagnostic tools. Among several faulty operations, flooding, drying and reactants' starvation conditions are considered. To this purpose, the operating variables are suitably set, so as to be consistent with the possible improper conditions that can occur into a real PEM fuel cellbased back-up system. The stack characterization, along with the first results in faulty conditions and the degraded mode are then presented. Afterwards, the acquired EIS spectra are analyzed in order to fix the main descriptors (features) for diagnosis purposes. A generic set of features has been proposed and considered during the EIS data analysis. Results have shown that the proposed set of features is useful for fault detection; however, the fault isolation process can require more information to discriminate the features' intensities. In this framework, on-going experimental activity mostly focuses on reproducing different level of the faulty conditions, whereas future works are mainly oriented to the relevant features extraction for multi-fault diagnostic algorithms implementation. Finally, EIS spectra analysis is also scheduled in case of unrecoverable degradations in order to develop new adaptive diagnostic tool able to take into account the FC ageing phenomena.

\section{Acknowledgements}

The research leading to these results has received funding from the European Union's Horizon2020 Program
(2020-JTI-FCH-2014-1) for the Fuel Cells and Hydrogen Joint Undertaking, under grant agreement number 671486 Research and Innovation Project : HEALTH-CODE (Real operation pem fuel cells HEALTH-state monitoring and diagnosis based on dc-dc Converter embeddeD Eis). Website: http:/ / pemfc. health-code.eu/

\section{References}

[1] R. Petrone, D. Hissel, M. C. Péra, D. Chamagne, R. Gouriveau, Int. J. Hydrogen Energy 2015, 40, 12489.

[2] R. Borup, J. Meyers, B. Pivovar, Y. S. Kim, R. Mukundan, N. Garland, D. Myers, M. Wilson, F. Garzon, D. Wood, P. Zelenay, K. More, K. Stroh, T. Zawodzinsky, J. Boncella, J. E. McGrath, M. Inaba, K. Miyatake, M. Hori, K. Ota, Z. Ogumi, S. Miyata, A. Nishikata, Z. Siroma, Y. Uchimoto, K. Yasuda, K. Kimijima, N. Iwashita, Am. Chem. Soc. 2007, 107, 3904.

[3] A. de Brujin, V. A. T. Dam, G. J. M. Janssen, Fuel Cells 2008, 8 (1), 3.

[4] W. Schmittinger, A. Vahidi, J. Power Sources 2008, 180, 1.

[5] J. Wu, X. Z. Yuan, J. J. Martin, H. Wang, J. Zhang, J. Power Sources 2008, 184, 104.

[6] R. Petrone, Ph.D. Thesis, University of Salerno, Salerno, Italy, 2014.

[7] R. Petrone, Z. Zheng, D. Hissel, M. C. Péra, C. Pianese, M. Sorrentino, M. Becherif, N. Yousfi-Steiner, Int. J. Hydrogen Energy 2013, 38 (17), 7077.

[8] Z. Zheng, R. Petrone, M. C. Péra, D. Hissel, M. Becherif, C. Pianese, N. Yousfi-Steiner, M. Sorrentino, Int. J. Hydrogen Energy 2013, 38 (21), 8914.

[9] Z. Zheng, M. C. Péra, D. Hissel, M. Becherif, K. S. Agbli, Y. Li, J. Power Sources 2014, 271, 570.

[10] N. Fouquet, C. Doulet, C. Nouillant, G. DauphinTanguy, B. Ould-Bouamama, J. Power Sources 2006, 159 (2), 905.

[11] X. Yan, M. Hou, L. Sun, D. Liang, Q. Shen, H. Xu, P. Ming, B. Yi, Int. J. Hydrogen Energy 2007, 32, 4358.

[12] F. Zhou, S. J. Andreasen, S. K. Kær, D. Yu, Int. J. Hydrogen Energy 2015, 40, 2833.

[13] J. P. Meyers, R. M. Darling, J. Electrochem. Soc. 2006, 153 (8), 1432.

[14] M. Dou, M. Hou, D. Liang, Q. Shen, H. Zhang, W. Lu, Z. Shao, B. Yi, J. Power Sources 2011, 196, 2759.

[15] A. Taniguchi, T. Akita, K. Yasuda, Y. Miyazaki, Int. J. Hydrogen Energy 2008, 33, 2323. 